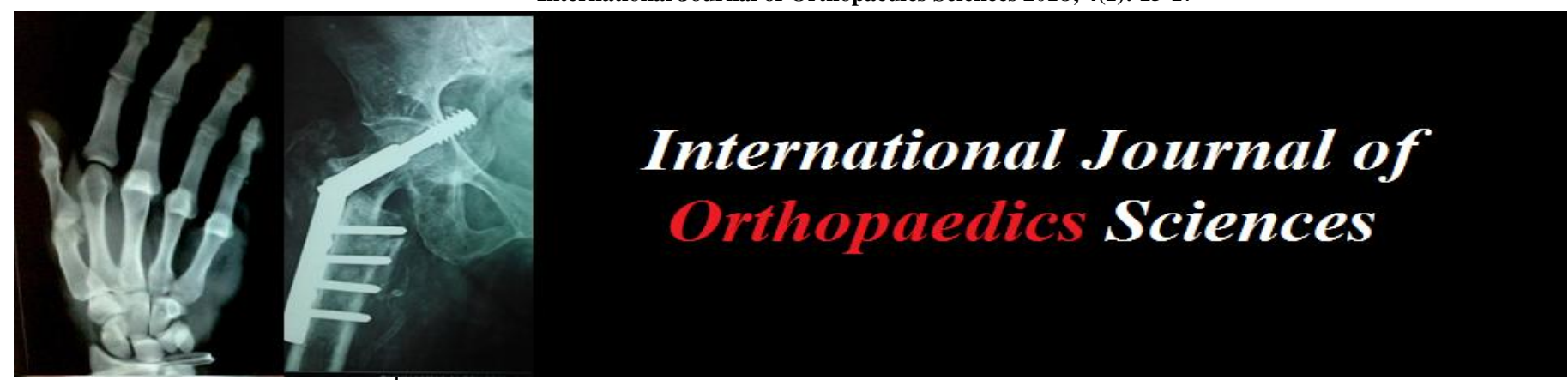

ISSN: $2395-1958$

IJOS 2018; 4(1): 15-17

(C) 2018 IJOS

www.orthopaper.com

Received: 05-11-2017

Accepted: 06-12-2017

Dr. Sahil Kohli

M.M. Institute of Medical

Sciences and Research, Mullana,

Ambala, Haryana, India

Dr. J Sikdar

M.M. Institute of Medical

Sciences and Research, Mullana,

Ambala, Haryana, India

\section{Management of proximal humerus fracture with PHILOS (Proximal Humerus Internal Locking System): A prospective study}

\section{Dr. Sahil Kohli and Dr. J Sikdar}

DOI: https://doi.org/10.22271/ortho.2018.v4.i1a.04

Abstract

Proximal humeral fractures may present with many different configurations in patients with varying comorbidities and expectations. The PHILOS plate is preffered for long fractures because the plate is available in longer sizes and provides greater stability as it has a greater number of screws in the head area and greater variability and perehaps higher stability. This study was done to analyse union rate and shoulder joint function after fixation of proximal humerus fracture with PHILOS. We prospectivley reviewed thirty patients with proximal humerous fracture treated with PHILOS at M.M.I.M.S.R, Mullana. Serial follow up assessment was done for radiological and clinical union. Most common complication included superficial infections. It was concluded that fixation with PHILOS plate is a nearideal technique with a high union rate.

Keywords: Proximal humerus fracture, PHILOS, Radiological union

\section{Introduction}

The management of fractures of the proximal humerus have challenged medical practitioners since the earliest recorded medical texts. Fractures of the proximal humerus represents $5 \%$ of all extremity fractures. Proximal humerus fractures have been a challenge to achieve stable fixation. Defining correct treatment options is becoming increasingly important, as the prevalence of osteoporotic fractures of the proximal humerus are expected to rise in the next three decades, and the functional outcome achieved after treatment may determine a patient's level of independence. PHILOS is part of the latest generation of locking compression plates for proximal humeral fracture fixation. Many complications of proximal humeral fracture including non-union, mal-union, avasular necrosis, rotatorcuff impingement and implant failure have been reported. The PHILOS plate has been introduced to reduce these complications.

\section{Methods}

Thirty patients of proximal humerous fracture were treated with PHILOS. Among 30 patients 10 were males and 20 were females having age between 20-80 years. Inclusion criterias: displaced fractures of proximal humerus in which fragments were displaced more than one centimetre or angulation was greater than 45 degree, old non-united fractures of proximal humerus, and proximal humerus fractures with distal extension into the humeral shaft. These 30 fractures were fixed within 7 days by PHILOS. Preoperative planning was done to assess the proper size of PHILOS plate. 


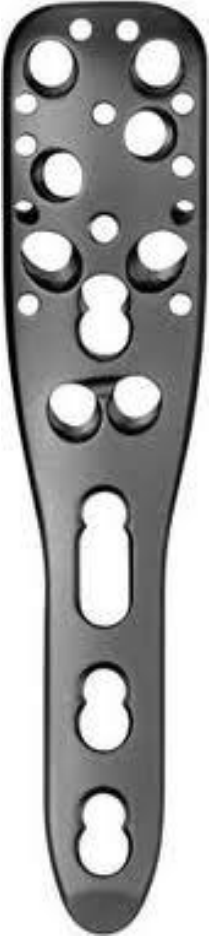

PHILOS plate

\section{Procedure}

The patient was placed in beach chair position or supine position depending on surgeon or anaesthetist's choice. Proximal humerus was exposed by deltopectoral approach. Direct or indirect fracture reduction was then achieved and provisional stabilization by Kirschner wires was done. Then appropriate plate was centered against the lateral aspect of the greater tubercle and about $10 \mathrm{~mm}$ below it to avoid subacromial impingement. The plate was fixed to the shaft of the humerus through proximal oval hole. Arming block was fixed to the plate and proximal holes were drilled using 2.8 $\mathrm{mm}$ drill bit and $3.5 \mathrm{~mm}$ locking head screws were fixed. The tip of the screws were always kept $5 \mathrm{~mm}$ away from the circumference of the head because the fracture fragment may collpase during the course of healing. Finally, the plate was fixed to humeral shaft either by cortical screws or locking head screws, depending on bone quality.

\section{Post-operative care $\&$ follow-up}

Arm pouch sling was applied. Limb elevation and active finger movements were advised. Shoulder and elbow exercises within the limit of tolerance were started as soon as pain subsided. Stitches were removed from $11^{\text {th }}-14^{\text {th }}$ day as per the condition of operative wound. All patients were followed up at monthly intervals for a minimum period of six months. During the period, patient was motivated for physiotherapy and gradual normal use of the affected limb. Fracture union was assessed clinically and radiologically. Shoulder function was evaluated and compared with the normal side as per Constant scoring system.

\section{Result}

Female to male ratio was $2: 1$ and age ranged from 20 to 80 years. Fifteen cases were two-part, 9 were three-part, and 6 were four-part fracture (Neer classification). Distribution of patients according to time taken for radiological union is shown in table 1 . The complications which were noted are shown in table 2 . The mean time for radiological union was 11.5 weeks. Out of 30 cases, 8 were excellent, 15 good, 5 fair, and 2 were reported as poor.
Table 1

\begin{tabular}{|c|c|c|}
\hline Time (in weeks) & No. of cases & Percentage \\
\hline $8-10$ & 10 & 33.3 \\
\hline $11-12$ & 13 & 43.3 \\
\hline $13-14$ & 4 & 13.3 \\
\hline $15-16$ & 2 & 6.7 \\
\hline$>16$ & 1 & 3.3 \\
\hline
\end{tabular}

Table 2

\begin{tabular}{|c|c|c|}
\hline Complications & No. of cases & Percentage \\
\hline Avascular necrosis of head & 1 & 3.3 \\
\hline Delayed union & 1 & 3.3 \\
\hline
\end{tabular}

\section{Discussion}

Proximal humeral fractures are challenging to treat. The form of plate system is anatomical and shaped to accomodate the junction of the humeral head and the shaft. In the area of the humeral head, the plate has, in addition to the holes for the locking head screws, small holes in order to fix the rotator cuff with sutures or cerclage wires. The screw holes of the plates in the area of the humeral head have been designed exclusively for the insertion of locking head screws for safer fragment fixation. The special arrangement of the locking head screws ensures a high level of stability. Due to its flat profile, the plate can also be fixed in a very proximal position, without causing imoingement later when the range of motion is good. With the locking plate system, there is also in principle the possibility of inserting the plate via a minimally invasive approach in the manner of a biological osteosynthesis.

The PHILOS plate can therefore provide an excellent stable construct even in multifragmented osteoprotic proximal humerus fractures. PHILOS uniformly leads to a satisfactory functional outcome over long term follow up. Although the results are poorer in old aged individuals with osteoporosis, they are nevertheless better than those achieved by nonlocking plates.

\section{Conclusion}

Indications for open reduction internal fixation techniques of proximal humerus have expanded with the introduction of locking plate technology. Internal fixation with PHILOS plate seems to be a reliable option in the operative treatment of humeral fractures, especially in osteoporotic bone. It allows secure fracture fixation and quick shoulder mobilization, while quick and uneventful fracture healing and very satisfactory clinical results are achieved. Operative stabilization of the proximal humeral fracture, especially in view of its frequency, will certainly remain a topical subject in future. At the moment, however, PHILOS plates are the standard implants for injuries of the proximal humerus.

\section{References}

1. Mauro CS. Proximal Humerus Fractures. Curr Rev Musculoskelet Med. 2011; 4(4):214-20.

2. Strohm PC, Helwig P, Konard G, Sudkamp NP. Locking Plates in Proximal Humerus Fractures. Acta Chirurgiae Orthopaedicae Et Traumatologiae Cechosl. 2007; 74: 410-5.

3. Brorson S. Management of Proximal Humeral Fractures in the Nineteenth Century: An Historical Review of Preradiographic Sources. Clin Orthop Relat Res. 2011; 469(4):1197-206.

4. Gerber C, Werner CM, Vienne P. Internal Fixation of Complex Fractures of the Proximal Humerus. J Bone 
Joint Surg Br. 2004; 86(6):848-55.

5. Leonard M, Mokotedi L, Alao U, Glynn A, Flemimg P. The use of Locking Plates in Proximal Humeral Fractures: Comparison of Outcome by Patient age and fracture pattern. Int J Shoulder Surg. 2009; 3(4):85-9.

6. Shahid R, Mushtaq A, Northover J, Maqsood M. Outcome of Proximal Humerus Fractures Treated by PHILOS Plate Internal Fixation Experience of a District General Hospital. Acta Orthop Bleg. 2008; 74:602-8.

7. Aggarwal S, Ball K, Dhillon MS, Kumar V, Mootha AK. Displaced Proximal Humeral Fractures: an Indian Experience with Locking Plates. Journal of Orthopaedic Surgery and Research. 2010; 5:60.

8. Khemlnitskaya E, Lamont LE, Taylor SA, Lorich DG, Dines DM, Dines JS. Evaluation and Management of Proximal Humerus Fractures. Advances in orthopaedics, 2012. DOI:10.1155/2012/861598. 